\title{
Espaço, Mídia Locativa e Teoria Ator-Rede
}

\begin{abstract}
Resumo: O social é o que emerge das associações, diz a Teoria Ator-Rede (TAR). As associações entre actantes (aquilo que produz uma ação) humanos e nãohumanos são sempre localizadas. A TAR busca analisar como se dão as associações e suas localizações para conhecer o social. Esse tipo de enfoque sobre o social pode ser particularmente interessante para se pensar a espacialização nos processos comunicacionais e, mais ainda, naqueles emergentes com as atuais mídias de geolocalização". Esse artigo se insere em uma pesquisa maior sobre as "mídias locativas" a partir da TAR. Aqui discutimos, particularmente, a noção de espaço.
\end{abstract}

Palavras-Chave: Espaço. Mídia Locativa. Teoria Ator-Rede.

\begin{abstract}
Space, locative media and actor-network theory- The social is what emerges from associations, according to actor-network theory (ANT). Associations between human and non-human actors (everything that produces action) are always localized. ANT attempts to analyze how these associations and their localizations are created. This is to know the social. This kind of associative focus on the social may be particularly interesting to identify spatialization in communication processes, as well as in processes emerging through current geolocation media. This article is part of a broader research on "locative media" based on ANT. Here we discuss, in particular, the notion of space.
\end{abstract}

Keywords:space, locative media, actor-network theory

\section{Introdução}

A TAR oferece um olhar sobre as noções de espaço e lugar, de micro e macro, de estruturas e de interações locais. Abolindo noções de escala, ela só vê conexões e articulações entre actantes em um espaço relacional de topologia plana. Lugares são redes de atores que conectam sempre outros lugares e temporalidades. Não é o global no local, nem o local além do global, nem mesmo o "glocal”. Vamos analisar essa questão em diálogo com a perspectiva da ontologia orientada a objetos de G. Harman, do correlacionismo de Q. Meillassoux e da teoria da "assemblage" (agenciamento) de M. DeLanda. A tese que sustento, a partir da TAR, é que devemos ver o espaço como uma "rede".

\section{Espaço-Rede}

Rede, para a TAR, não é infraestrutura, mas o que é produzido na relação entre humanos e não humanos. Não estamos falando de redes de computadores, de redes sociais, de

\footnotetext{
${ }^{1}$ Mídias de geolocalização ou mídias locativas são tecnologias e serviços baseados em localização. Ver Lemos (2010).
} 
redes de esgoto... Rede é aqui um conceito dinâmico. Não é o que conecta, mas o que é gerado pelas associações. Não é algo pronto, por onde coisas passam, mas o que é produzido pela associação ou composição de atores humanos e não-humanos. Rede não é estrutura, mas o que é tecido em uma dada associação. Quando falamos de rede, estamos falando de mobilidade. Ao olharmos o mundo, vemos redes se fazendo e se desfazendo a todo momento. O conceito de rede visa apreender algo pulsante, o que se forma e se deforma aqui e acolá pela dinâmica das relações. Para Latour (2005, p. 129):

\begin{abstract}
Thus, the network does not designate a thing out there that would have roughly the shape of interconnected points, much like a telephone, a freeway, or sewage 'network'. It is nothing more than an indicator of the quality of a text about the topics at hand. It qualifies its objectivity, that is, the ability of each actor to make other actors do unexpected things. A good text elicits networks of actors when it allows the writer to trace a set of relations defined as so many translations.
\end{abstract}

A intenção desse artigo é fazer uma correlação entre as noções de espaço e rede, no sentido dado a essa última pela TAR. Há duas noções importantes para compreensão do espaço: 1. Espaço como conceito abstrato (matemático, reservatório de todas as coisas) e, 2. Espaço como aquilo que é constituído pela distensão dos lugares (construídos historicamente), como relacional e dinâmico. Na primeira acepção, espaço é o reservatório de todas as coisas e concebido como uma entidade matemática. Aqui as coisas e os lugares estão em um espaço à priori. Na segunda acepção, o espaço é uma rede de lugares ${ }^{2}$ e objetos que vai se formando pelas dinâmicas desses últimos. O espaço deve ser compreendido em suas duas dimensões (abstrata e o relacional). No entanto, para pensar a comunicação e as mídias locativas, talvez seja mais interessante nos concentrarmos no espaço relacional, como uma rede que é produzida nas relações entre coisas historicamente constituídas.

O espaço é um "espaço-rede”, dinâmico, infinito, configurando-se na dinâmica das associações. Podemos exemplificar com o espaço que vamos criando ao deslocarmos móveis em uma sala; ou na rua, ao construirmos novos equipamentos urbanos; ou na cidade, ao criar ruas, praças, monumentos; ou no planeta, ao ampliar as coisas na terra, no céu e no mar; ou mesmo no cosmos, ao distendermos o "nosso" espaço com satélites e viagens espaciais. Aqui o espaço não é aquilo que contém coisas, mas o que está a se construir, como a noção de rede para a TAR. Para a análise social e comunicacional devemos observar como o espaço se

\footnotetext{
${ }^{2}$ Lugares podem ser pensados como o conjunto de localização, local e relações sociais (localização: latitude e longitude; local: cidade, bairro, rua; e as relações que aí se desenvolvem). Quanto mais lugares/objetos, mais "espaçamentos" vão sendo criados por suas relações.
} 
conforma e se deforma na dinâmica das associações. Acredito que compreender essa dinâmica é fundamental para descrevermos as produções sociais do espaço pelas mídias.

\section{Correlacionismo}

A visão de um "espaço-rede" relacional e não abstrato, pode ser também corroborada pela filosofia correlacionista de Quentin Meillassoux. Para o filósofo francês, é correto afirmar que o sensível só existe na nossa relação com o mundo. Mas, por outro lado, algumas propriedades (matemáticas) são intrínsecas aos objetos. Estas podem ser concebidas se estivermos, ou não, próximos ou em relação ao objeto. $\mathrm{O}$ correlacionismo propõe que é impossível ter acesso às coisas nelas mesmas. Como diz Meillassoux, "we only ever access to the correlation between thinking and being, and never to either term considered apart from the other." (Meillassoux, 2008, location $92^{3}$ ). Nunca apreendemos o objeto isolando-o de sua relação com o sujeito, assim como nunca apreendemos o sujeito fora de sua relação com o mundo. Esse é o círculo do correlacionismo, que será contestado por Harman, como veremos mais adiante. Só podemos ter acesso à correlação entre pensamento e ser. O mundo aparece para mim como mundo por estar aí. Mas o sujeito só é sujeito quando está perante esse mesmo mundo. Essa é a correlação! Para Meillassoux, até Kant, o problema da filosofia era apreender a verdadeira natureza da substância. Depois de Kant, a questão passa a ser a de saber quem apreende melhor as correlações (filosofia analítica ou fenomenologia, por exemplo).

Há aproximação e distanciamento entre o correlacionismo de Meillassoux e a TAR de Bruno Latour. Latour afirma que quanto mais objetos, mais sujeitos e quanto mais sujeitos, mais objetos, o que é muito próximo do correlacionismo. No entanto, o correlacionismo se afasta da TAR ao reconhecer uma propriedade do mundo externo fora das relações entre as coisas. Na concepção da TAR, não há essências. Tudo deriva da relação entre actantes ${ }^{4}$.

\footnotetext{
${ }^{3}$ Localização usando uma versão do livro no "Kindle" (onde não há páginas), sem mudança de tamanho de fonte.

${ }^{4}$ Para Meillassoux, durante o século XX as principais mídias dessa correlação foram a consciência (a filosofia analítica) e a linguagem (a fenomenologia). O que Francis Wolff chama de "objeto-mundo". Estamos presos na consciência ou na linguagem. Ser consciente da árvore é ser consciente da árvore em quanto que árvore e não da ideia de árvore. E isso se faz falando da árvore. Consciência e linguagem fecham o mundo como se estivéssemos em uma jaula transparente. A linguagem e a consciência nos transcendem em direção ao mundo, mas só fazem isso por existir um mundo lá fora, que reflexivamente é correlativo a nossa própria existência na consciência e na linguagem. Assim, não nos transcendemos entrando no mundo já que estamos face a face. Para Meillassoux, a correlação entre pensamento e ser não é a mesma coisa e não pode ser reduzido à correlação sujeito e objeto. Não pode ser reduzida a uma filosofia da representação (Meillassoux, 2008).
} 
Como afirma G. Harman (2009), Latour é um correlacionista a meio termo. Diferente de Meillassoux, ele não acredita que algo preexista às relações. Se não há relação, não há ator, não há nada. Um actante é o que modifica, transforma, o que perturba ou cria. Podemos pensar que é aquilo que produz uma diferença. Talvez seja interessante pensar o actante a partir dessa perspectiva informacional, como aquela diferença que faz diferença (Bateson). Se não há diferença, não há perturbação, ação ou criação. Essência é existência e existência é ação, diz Latour. Para a TAR, não há potência ou essência, pois tudo se resume às relações. Como afirma Harman, para Latour, "an actor is completely actualized in any moment, inscribed without reserve in its current scheme of alliances" (Harman, 2009, p. 127) ${ }^{5}$.

Voltando à ideia de espaço, podemos dizer que a nossa relação correlacionista com o mundo se dá na produção do espaço. O próprio do homem é produzir espacialização. É o seu modo de existência. Aqui podemos dizer que tanto Meillassoux como Latour apontam para uma visão do espaço como rede que se faz na associação ou correlação (que não são a mesma coisa, mas apontam para a dimensão relacional e produtiva da espacialização). Martin Heidegger é importante nesse contexto. Para o filósofo alemão, o espaço é concebido como vorhanden (present-at-hand, o objeto nele mesmo, "teoria") e zuhanden (ready-to-hand, o objeto para o nosso uso, a "região", o lugar por onde nos deslocamos, "prática") 6 . Para Heidegger, o homem não existe no espaço da mesma forma que os outros animais ou coisas. Existimos produzindo espacialização, sendo esse o nosso modo de existência, o Dasein. Esse modo de existência se dá por dois outros componentes: a de-severance (aquilo que está próximo ou distante) e a directionality (a orientação do movimento). Assim, o espaço não é abstrato, mas o que se cria nas relações entre as coisas construídas. Como afirma Heidegger, "une espace (Raum) est quelque chose qui est "ménagé' (...) il est ménagé par des lieux..." (Heidegger, 1958, p. 186). A espacialização do homem por meio da técnica já foi para além do "reservatório" do planeta. Ampliamos o espaço rede pelas redes técnicas. Como explica Arisaka,

\footnotetext{
${ }^{5}$ Harman vai se posicionar contra essa visão relativista de Latour. Para o filósofo americano, não existiria uma democracia total dos objetos, ou mesmo uma ontologia plana (flat ontology). Ver as diferenças entre os dois na segunda parte do "Prince of Networks" (Harman, 2009)

${ }^{6}$ Não tenho tempo para fazer uma discussão mais profunda sobre essas noções. Elas mostram uma dependência do objeto em relação ao sujeito (zuhanden), e o objeto em sua existência não relacional (vorhanden). Para uma explicação nesse sentido, ver Harman (2011). "No matter how hard I work to become conscious of things, environing conditions still remain of which I never become fully aware. When I stare at a river, wolf, government, machine or army, I do not grasp the whole of their reality. This reality slips from view into a perpetually veiled underworld, leaving me with only the most frivolous simulacra of these entities (...). The readiness-to-hand of an entity is not exhaustively deployed in its presence-at-hand" (Harman, 2011, p. 39).
} 
Heidegger's theory rejects the absolute theory's claim that space is an independent entity. His theory, however, retains some elements from the relational theory. Though Heidegger would not reduce space to physical entities and their relations, there is a sense in which he treats space as coextensive with our daily actions, or what Heidegger calls the "care structure." De-severance, directionality and regionality just are the various ways in which Dasein exists as care, together with temporality. Spatiality describes Dasein's relational dealings with entities within the world, and there is no space "beyond" this spatiality of Being-in-the-world. Neither Dasein nor entities exist independently of each other "in" some empty space, but rather, Dasein and entities are essentially spatial. (Arisaka, 1995. p. 460)

\section{Ontologia Orientada a Objeto (OOO)}

A OOO de Harman propõe ver o espaço como uma dimensão que emerge das qualidades dos objetos. Os objetos podem ser colocados na perspectiva de um quadrante onde aparecem o "objeto sensual" (o que se dá à consciência), o "objeto real" (que se retira e é impossível de ser conhecido), a "qualidade sensual" (as que percebemos pelos sentidos) e a “qualidade real” (acessível intelectualmente). Para Harman (2011, p. 49)

While there may be an infinity of objects in the cosmos, they come in only two kinds: the real object that withdraw from all experience, and the sensual object that exist only in experience. And along with these we also have two kinds of qualities: the sensual qualities found in experience, and the real ones that Husserl says are accessible intellectually rather than through sensuous intuition.

Nesse objeto quádruplo, Harman defende a existência dos objetos para além de suas relações, diferenciando-se de Latour (Harman 2011) e Meillassoux. Para o que nos interessa aqui, Harman propõe pensar o espaço a partir desse quadrante de quatro tensões que define a sua ontologia dos objetos ${ }^{7}$.

A primeira tensão é aquela entre o "objeto sensual" ou intencional e suas "qualidades sensuais". Isso é o que entendemos por tempo. Como explica Harman:

There would be no sense of time if we could not experience streets or plastic bottles under subtly shifting conditions from one instant to the next. The feeling that time is flowing along is in fact a sense of the swirling play of accidents on the surface of slightly deeper intentional objects. (2009, p. 217).

\footnotetext{
${ }^{7}$ É nesse quadrante que as diferenças entre Latour e Harman tornam-se claras. Harman sustenta que o objeto tem uma essência e que ele não é dependente de suas relações. Posição contrária à Latour. Vou me concentrar na primeira e na segunda tensões. Para efeito de esclarecimento, indico rapidamente a terceira e quarta. A terceira tensão é a "essência", relação entre o "objeto real" e a "qualidade real". A quarta tensão é a que emerge do "objeto sensual" e suas "qualidades reais". Essa tensão é o "eidos”. (Harman, 2009 e 2011).
} 
A segunda tensão é o espaço. É a tensão entre um "objeto real” e suas "qualidades sensuais" através das quais ele é acessível "differently" (Harman, 2009, p.128). O conceito se aproxima mais uma vez de espaço como relação e não como reservatório. O próprio Harman chama a atenção mostrando que o conceito de espaço adotado aqui é o mesmo de Leibniz:

Space is not the site of relation, but of both relation and non-relation. We have a strong pre-philosophical grasp of this teaching: space is a medium in which I can fly to Bangkok or Dubai, but also one in which I am not currently in those places. Space is both nearness and distance. Things make contact along specific surfaces but are not exhausted by this contact, and recede partially into private depths. (Harman, 2009, p. 218).

O espaço é consequentemente relacional e pode ser compreendido como rede no seu sentido dado pela TAR. O correlacionismo de Meillassoux, a espacialização do Dasein em Heidegger e o quadrante da ontologia dos objetos de Harman reforçam essa tese, mesmo que haja diferenças e divergências importantes entre os autores (não temos tempo para expô-las aqui). Nesse sentido, o espaço pode ser entendido para além da ideia de uma infraestrutura por onde passam coisas e ser apreendido em sua dinâmica móvel e associativa. Ele é constituído por atravessamento de fluxos e por dinâmicas que vão além de uma ação do micro no macro e vice-versa. É em abolindo essas escalas que o analista social pode visualizar os movimentos associativos dos actantes sem enredá-los em estrutura (macro) ou no interacionismo (micro).

É interessante notar como, por analogia, podemos ver o ciberespaço a partir dessa perspectiva. Ele é espaço abstrato, enquanto infraestrutura planetária de redes telemáticas interligando computadores. Mas ele é espaço relacional, ou espaço-rede, em formação permanente pela articulação de objetos, humanos e não-humanos. Ao pensar o ciberespaço como espaço-rede, podemos escapar do micro e da macro dimensões e ver, para além das grande chaves explicativas, o movimento, as associações, o social se formando e se deformando. O espaço do "ciber-espaço" é esse espaçamento produzido pelos lugares, coisas, pessoas e objetos conectados ao redor do planeta. Por isso, ele está sempre em construção. A internet vai produzindo espacialização na relação dos lugares e nas movimentações pelas conexões de tudo e todos, em um espaço de controle que se faz e se desfaz nesse movimento, no tempo. Esse é outro ponto que gostaríamos de explorar com a "Assemblage Theory" de Manuel DeLanda.

\section{Agenciamentos, Montagem, Composição}


O trabalho do filósofo Manuel DeLanda traz uma contribuição interessante a esse debate. O que DeLanda chama de "Assemblage Theory" (AT), pode ser pensada como similar à teoria das totalidades especiais (Gabriel de Tarde), da monadologia (Leibniz), das associações híbridas (Latour), do agenciamento (Deleuze). Muitos têm traduzido assemblage por agenciamento, devido à evidente e reconhecida inspiração da ideia de exterioridade de Deleuze. Parece, no entanto, que o termo, sendo traduzido por montagem ou composição, ofereceria uma visão mais próxima da ideia de associação, de hibridismo entre humanos e não humanos da TAR. Tanto para a TAR como para a AT, as associações não podem ser pensadas nem como totalidade, nem como possuindo uma essência que anularia as particularidades de suas partes. Pensar o espaço como composição dessa natureza nos ajudaria a reforçar a relação complexa entre as micro e macrodimensões do social. É como se essas dimensões não existissem. Para DeLanda (2006, p. 17),

The combination of recurrence of the same assembly processes at any one spatial scale, and the recurrence of the same kind of assembly processes (territorialization and coding) at successive scales, gives assemblage theory a unique way of approaching the problem of linking the micro- and macro-levels of social reality.

DeLanda defende uma ontologia social realista na qual a existência das instituições e das organizações sociais, das redes interpessoais e de outras entidades são tratadas diferentemente em relação ao construtivismo (fenomenologia). O social é um agenciamento, fruto de processos históricos e não apenas da linguagem. Não há micro e macro dimensões, como estruturas e agencias, mas um conjunto que não é redutível às suas partes, sendo criado por causalidades recorrentes e por contingências. Esses conjuntos não são uma totalidade. Ela não tem uma essência que comprometeria para sempre a sua existência. Para DeLanda, entender as composições do social é ir além dos reducionismos, dos micros ou macros determinismos. O primeiro (micro) considera o nível da racionalidade do indivíduo e da microeconomia como determinantes da experiência pessoal. É o construtivismo social. O segundo (macro) pensa por estruturas. O social se dá nesses enquadramentos que não nega o indivíduo, mas coloca a sua formação subjetiva no seio de uma estrutura determinante (Durkheim, T. Parson, Marx, entre outros). Haveria também uma espécie de 
mesodeterminismo imputado a A. Giddens, misturando agência individual e estrutura social em uma relação dialética que anularia as polarizações ${ }^{8}$. Para DeLanda (2006, p. 5-6):

This is because assemblages, being wholes whose properties emerge from the interactions between parts, can be used to model any of these intermediate entities: interpersonal networks and institutional organizations are assemblages of people; social justice movements are assemblages of several networked communities; central governments are assemblages of several organizations; cities are assemblages of people, networks organizations, as well as of a variety of infrastructural components, from buildings and streets to conduits for matter and energy flows; nation-states are assemblages of cities, the geographical regions organized by cities, and the provinces that several such regions form.

Assim como Latour, DeLanda afirma que não há algo como "a sociedade como um todo". Ele recusa a metáfora orgânica. Esta seria fruto de analogias equivocadas entre o corpo humano e a sociedade, principalmente após Claude de Saint-Simon no século XIX. O que pensadores expõem como "organismo social" deve ser visto como composições, agenciamentos, nas quais as relações não são obrigatórias, ou essencialmente determinadas, mas contingentes. Agenciamentos são composições (podemos chamar de associações) que acontecem a partir de duas funções centrais (de suas partes). Por um lado, as capacidades expressivas e a materiais e, por outro, as funções de estabilização (e seu oposto). Essas funções (que são de suas partes na composição) agem aumentando (ou diminuindo) a homogeneidade interna e externa de suas fronteiras. DeLanda chama essa função de territorialização (ou desterritorialização). A territorialização se dá por codificação (controle): os genes e as palavras, o código genético e a linguagem ${ }^{9}$.

DeLanda mostra, por exemplo, que as novas mídias são vistas como desterritorializantes por, em determinados conjuntos (a relação face a face, por exemplo), mudar as condições de materialidade e de expressividade. Certamente, com a internet e o celular, a relação muda, não sendo mais aquela do compartilhamento de um mesmo contexto, ambiente ou lugar. Mas cria-se uma espacialização pela ação mediada. Esses dispositivos midiáticos, por instituírem uma descontinuidade nas relações face a face, engendram processos desterritorializantes (abrem-se as fronteiras, há interferências de lugares distintos, que atingem diferentemente os interlocutores etc.). Como afirma DeLanda, "finally, a

\footnotetext{
${ }^{8}$ Como exemplos de sociólogos que atuam fora desses determinismos, DeLanda cita Goffman (na sua microsociologia da conversação), Weber (sobre as instituições) e Tilly (na compreensão dos movimentos sociais)

9 Para AT, organismos vivos são "montados" por matéria e expressividade de suas partes que têm na territorialização ações dos genes e da linguagem. Da mesma forma as organizações sociais hierárquicas, que embora não tenham genes biológicos, mantêm a sua fronteira pela territorialização da linguagem.
} 
technological invention that allows a conversation to take place at a distance affects its identity not by changing it into some other form of social encounter but by blurring its spatial boundaries, forcing participants to compensate for the lack of co-presence in a variety of other ways." (2006, p.55).

No entanto, podemos dizer que outra associação se faz, outro conjunto é "territorializado". O uso constante dessas mídias criariam novas composições das relações interpessoais, novas regiões de fachada e de fundo (em sistemas como blogs, Twitter, Facebook, chats...). Da mesma forma, as mídias de geolocalização podem ser vistas compondo novas associações infocomunicacionais. Por um lado são desterritorializantes, mas por outro, criam territorializações ao reforçar sentidos de lugar e controle informacional. Por exemplo, ir a uma praça de alimentação de um shopping pela oferta de conexão Wi-Fi. O hotspot Wi-Fi age como catalisador, sendo mais um componente (actante) na constituição desse lugar. A conexão à internet pode "retirar" o usuário do lugar (ao conectá-lo ao ciberespaço), mas também reforçar antigos vínculos a esse mesmo lugar.

A aproximação entre AT e TAR é evidente e tanto Latour (2005) como Harman (2009) reconhecem essa similaridade ${ }^{10}$. Podemos dizer, falando pela AT, que: "As composições (sociais ou não) criam-se, desenvolvem-se e perecem pela dinâmica material e expressiva de suas partes. Estas agem territorializando e reforçando suas fronteiras por ações amplas onde a codificação genética e a linguagem operam”. Pela TAR diríamos: "As associações (que formam o social) criam-se, desenvolvem-se e perecem pela exercício sempre difícil da articulação da rede de actantes, criando temporariamente e localmente uma ação. Não há essência, mas as codificações genéticas e a linguagem podem ser actantes importantes em uma dada associação".

A manutenção de uma assemblage, ou associação, é sempre muito difícil e requer esforços dos actantes ou de suas partes. Isso se dá, obviamente, por processos recorrentes que fazem com que uma determinada associação possa se manter por muito tempo, e ainda gerar associações maiores. Para DeLanda, não devemos associar rapidamente a ligação entre componentes como interioridade ou essência. A interação dos genes com o maquinário orgânico não pode ser visto como aquilo que define a essência desse mesmo maquinário. Da

\footnotetext{
${ }^{10}$ Sobre as relações de proximidade e distanciamento entre o pensamento de Latour e DeLanda, ver o excelente texto de Harman (2007).
} 
mesma forma, não podemos definir o sujeito apenas pala interação pela linguagem, ou pela instituição social:

In an assemblage approach, genes and words are simply one more component entering into relations of exteriority with a variety of other material and expressive components, and the processes of coding and decoding based on these specialized lines of expression operate side by side with nongenetic and nonlinguistic processes of territorialization and deterritorialization. (DeLanda, 2006, p.16)

A estabilidade e o crescimento só podem ser vistos à posteriori, fruto de propriedades emergentes, sem essência, gerando eventos em uma mistura complexa de "causas, razões e motivos", como coloca Max Weber (citado por DeLanda). Assim com a TAR, a AT não permite pressupor generalidades reificadas ou essências. Só há, como afirma DeLanda, naturezas contingenciais das generalidades. Uma espécie animal, por exemplo, deve ser vista como uma entidade individual, tão única quanto os organismos que a compõem, mas maior em escala espaço-temporal. Ela não é uma categoria geral, ou um "tipo natural” (Aristóteles), que marcaria uma essência de todos os seus exemplares. Esse tipo de análise, equivocada para DeLanda e Latour, parte sempre de uma generalização, descobre suas supostas lógicas internas e, a posteriori, constrói o que seria a estrutura ou a "essência". Da mesma forma, a "sociologia do social" parte de generalizações para enquadrar os actantes em estruturas ou essências, de trás para a frente. DeLanda (2006, p. 28) esclarece:

\begin{abstract}
Assemblage theory (...) avoids taxonomic essentialism through this manoeuvre. The identity of any assemblage at any level of scale is always the product of a process (territorialization and, in some cases, coding) and it is always precarious, since other processes (deterritorialization and decoding) can destabilize it. For this reason, the ontological status of assemblages, large or small, is always that of unique, singular individuals. In other words, unlike taxonomic essentialism in which genus, species and individual are separate ontological categories, the ontology of assemblages is flat since it contains nothing but differently scaled individual singularities (or hacceities). As far as social ontology is concerned, this implies that persons are not the only individual entities involved in social processes, but also individual communities, individual organizations, individual cities and individual nation-states.
\end{abstract}

Assim, se algo se repete, não devemos falar de estruturas ou essências, mas de "singularidades universais". As diferenças que surgem nesses sistemas não são atribuídas a uma diferenciação lógica, mas sempre histórica. Para DeLanda, o conjunto de singularidades universais é o que Deleuze chama de diagrama. Ele organiza o espaço de possibilidades de uma determinada associação. Pessoas, instituições e mesmo uma nação (todas singularidades individuais) têm seus espaços de possibilidades (seus graus de liberdade) organizados a partir de um arranjo de singularidades universais. Um exemplo dessas singularidades universais é o 
que Weber chama de "ideal tipo". Ele não é uma essência, mas um diagrama". Singularidades universais e individuais permitem que a teoria das montagens possa atuar sem falar de essências. O que a aproxima da TAR.

\section{Teoria Ator-Rede}

Vimos como a AT em muito se aproxima da TAR. Ambas pensam as associações entre humanos e não humanos onde não há essência, mas relações emergentes (diagramas) que podem, por contingência, se manterem. A relação espacial pode assim ser pensada. Não há um global agindo sobre o local, nem um local, independente do global. Há conjuntos mais ou menos estáveis que se interpenetram e constituem associações para determinada ação nas quais localizadores ou articuladores e plug ins (Latour, 2005) colocam em partilha tempos e lugares distintos. Cabe ao analista social sair da armadilha de ter que escolher o seu lugar de análise, seja a partir do "macro" (o global, o contexto, a estrutura), seja a partir do "micro" (a agência individual, o interacionismo, a microeconomia). Pela comodidade de ter uma escala definida, um pólo de observação fixo, o analista faz desaparecer a dinâmica social. As associações não mais podem ser vistas já que rastros dos actantes são apagados em prol de uma resolução fixa de um "espaço" geral, ou de um "lugar" particular. No entanto, a ação dos actantes só pode ser vista se partimos de uma espacialização plana, sem escalas, como sugere a TAR.

Para a TAR, nenhuma relação pode ser vista como: Isotópica - tudo o que age em um lugar vem sempre de muitos tempos e lugares; Sincrônica - os lugares reúnem sempre actantes gerados em diversas temporalidades; Sinóptica - não é possível ter uma visão do todo; Homogênea - os lugares não tem as mesmas qualidades; ou Isobárica - as relações e pressões são diferenciadas onde intermediários transformam-se em mediadores e vice-versa. Isso nos permite deslocar a discussão sobre escalas, micro e macro. Não há nada, para a ANT, que possa ser pensada como global ou local. Para Latour (2005) há sempre uma relação entre localização e contexto a partir de articulators ou localizers (voltaremos a eles no final). O lugar não é independente do contexto, nem um mero refém deste. Há sempre um vai-e-vem entre diversos mediadores que conectam localidades e temporalidades fazendo do lugar o

\footnotetext{
${ }^{11}$ Para Deleuze a noção de diagrama é de uma máquina de possibilidades, abstrata como o "via a ser" que constitui a possibilidade de qualquer coisa. Não é a coisa, não a representa, mas é a sua possibilidade, causa dos agenciamentos (dai deriva a relação entre diagrama e dispositivo em Foucault). A "causa imanente" é para Deleuze o que existe entre o diagrama (a máquina abstrata) e os agenciamentos concretos. Ver Nabais (s.d.).
} 
resultado de um atravessamento de fluxos. Se o espaço é essa rede móvel de coisas e humanos, de lugares em mutação, de comunicação entre objetos e humanos, não há nunca uma coisa meramente local ou global.

É interessante ver como Latour, em um texto sobre a globalização (Latour, 2011), fala que para termos uma noção do seu significado, devemos olhar as coisas que estão ao nosso redor, ou as coisas de que necessitamos para viver e nos perguntar: de que espaços e tempos eles vêm? Pense na sua mesa e olhe para os objetos ao seu redor: de onde eles vêem, quando e onde foram feitos, quem pode consertá-los ou melhorá-los? Quanto mais distantes as coisas e as pessoas estiverem, maior é a sensação de globalização, de atravessamento de fluxos e maior também é a deformação do espaço e o cruzamento entre as micro e macrodimensões. $\mathrm{O}$ tempo, como uma dimensão do espaço, nada mais é do que aquilo que é produzido pela relação entre as coisas, pela sua dinâmica de constituição. As associações criam o tempo e o espaço, diz Latour. Eles aparecem nas montagens e composições.

Com o achatamento ontológico do espaço, não se trata nem de globalizar o lugar, nem de localizar o global, mas de pensar em suas redistribuições, gerando uma nova cartografia, mais dinâmica, menos generalista (espacial) e mais locativa. Essa cartografia teria o papel de mostrar os rastros deixados pelos actantes ${ }^{12}$. As tecnologias de informação e as redes telemáticas têm criado possibilidade de monitoramento dos dados sociais para diversos fins, inclusive de controle e de vigilância. Entretanto, essas tecnologias fornecem dados finos das associações, das variações, das adaptações e das redes que nenhuma estatística jamais pode oferecer. Essa cartografia de um espaço plano mostra os deslocamentos e distribuições, os rastros digitais, detectando movimentos para além de uma visão fixada à priori em dimensões do micro ou do macro, da estrutura ou da agência.

Como apontamos no início desse texto, Latour trata a relações com o espaço de forma relativista, a partir da noções de articuladores ou localizadores, e plug ins. Para entender as associações em um determinado espaço devemos buscar os rastros, os caminhos deixados pelos actantes que podem ser de inúmeras formas, mas que sempre estão marcados pelos seus lugares de produção e os locais de interação. Localizadores, articuladores e plug ins entram

\footnotetext{
12 "Cartografias de Controvérsias" é uma maneira de visualizar actantes em uma dada associação. Sobre esse tema ver o site do MACOSPOL (Mapping Controversies on Science and Politics), in http://www.medialab.sciences-po.fr/index.php?page=mapping-controversies-en http://mappingcontroversies.net/
} 
em jogo em toda associação. São eles que fazem a distribuição de uma composição ou associação:

In effect, what has been designated by the term 'local interaction' is the assemblage of all the other local interactions distributed elsewhere in time and space, which have been brought to bear on the scene through the relays of various non-human actors. It is the transported presence of places into other ones that I call articulators or localizers. (Latour, 2005, p. 194)

Articuladores e imutable mobiles ${ }^{13}$ fazem sempre circular actantes por espaço e tempos diferenciados. Olhar para articuladores (ou localizadores), plug ins e imutable mobiles só é possível tomando por base uma topologia plana, um espaço destituído de dimensões globais ou locais. No limite, tudo é localizado por atravessamento e circulação. Nenhum lugar é dominante o bastante para ser global, e nenhum lugar é autossuficiente para ser apenas local. Se pensarmos a partir de interação local ou global, não poderemos mais ver as conexões do social, não conseguiremos mais retraçar essas associações. Devemos evitar a tentação de aprisionar o social em duas caixas - a global e a local.

Os actantes estão sempre fazendo itinerários bizarros. O importante é estar atento ao que circula, à redistribuição de tempos e lugares em um espaço sem escalas. Assim pode-se detectar diversas outras entidades que se deslocam e cujos deslocamentos eram dificilmente detectáveis pelas escalas artificiais (macro ou micro). Como uma paisagem seca e empoeirada, explica Latour, deixa mais marcas, o espaço mais liso, sem escalas, sem estar previamente articulado entre estrutura e interação, entre macro e micro, deixa os rastros aparecerem. Eles não seriam mais submersos, sustenta a TAR, por uma estrutura ou pelo interacionismo da "Sociologia do Social"14.

Para explicar esse movimento, Latour toma emprestado da informática o termo plug in. Um plug in é um conjunto de instruções que acrescenta funcionalidades a um determinado programa. Colocamos um plug in em um navegador da internet para ver um vídeo. Ele traz algo de fora para ampliar uma função localizada. A ideia de plug in pode ser bem interessante para a discussão espacial, pois ela faz o trânsito e a circulação de entidades pelas dimensões do micro e o macro, criando localmente individualização, subjetivação, ou personalização nas associações. Como explica Latour (2005, p. 207):

\footnotetext{
13 A noção de imutable mobile é muito interessante e foi introduzida por Latour em "Science In Action" (Latour, 1987) para descrever deslocamentos com transformações. O jornal é um exemplo.

${ }^{14} \mathrm{O}$ termo é utilizado por Latour para diferenciar a TAR, uma Sociologia das Associações, da sociologia de herança durkheimiana.
} 
Surely the question we need to ask then is where are the other vehicles that transport individuality, subjectivity, personhood, and interiority? If we have been able to show that glorified sites like global and local were made out of circulating entities, why not postulate that subjectivities, justifications, unconscious, and personalities would circulate as well? And sure enough, as soon as we raise this very odd but inescapable question, new types of clamps offer themselves to facilitate our enquiry. They could be called subjectifiers, personnalizers, or individualisers, but I prefer the more neutral term of plug-ins, borrowing this marvelous metaphor from our new life on the Web. (...) Being a fully competent actor now comes in discreet pellets or, to borrow from cyberspace, patches and applets, whose precise origin can be 'Googled' before they are downloaded and saved one by one.

\section{Conclusão}

A alternância abrupta entre micro e macro, ator e sistema não é assim uma característica essencial do social, mas uma forma de encarar as associações criadas por uma determinada sociologia. Para a sociologia das associações, que é a TAR, deve-se evitar passar do contexto estrutural para as relações interativas da microssociologia, ou vice-versa. $\mathrm{O}$ interessante é poder olhar a circulação de actantes por entre essas instâncias sem congelar a análise. Se o analista decide de antemão em que escala vai trabalhar, fixando-se no macro, no contexto ou na estrutura de um lado, ou na interações, na particularidade e no micro de outro, o movimento e os rastros do social se perdem para sempre. Por isso pensar o espaço como relacional, espaço-rede, pode ajudar na análise das diversas associações que compõem as práticas comunicativas com as novas mídias de geolocalização. Como ensina Latour (2005, p. 231):

It is only by making flatness the default position of the observer that the activity necessary to generate some difference in size can be detected and registered. If the geographical metaphor is by now somewhat overused, the metaphor of accounting could do just as well - even though I may have used it too much already. The transaction costs for moving, connecting, and assembling the social is now payable to the last cent, allowing us to resist the temptation that scaling, embedding, and zooming can be had for nothing without the spending of energy, without recruitment of some other entities, without the establishment of expensive connections.

\section{Referências}

ARISAKA, Yoko. On Heidegger's Theory of Space: A Critique of Dreyfus. in Inquiry 38:4. December. pp. 455$467,1945$.

DELANDA, Manuel. A New Philosophy of Society. Assemblage Theory and Social Complexity. Continuum, London, NY. 2006.

HARMAN, G. (2007). Networks and Assemblages: The Rebirth of Things in Latour and DeLanda., disponível em

http://www.google.com.br/url?sa=t\&rct=j\&q\&esrc=s\&source=web\&cd=1\&cad=rja\&ved=0CCQQFjAA\&url=h 
ttp\%3A\%2F\%2Froundtable.kein.org\%2Ffiles\%2Froundtable\%2FLatour\%2520and\%2520DeLanda\%25202.doc $\underline{\text { \&ei }=x \text { fmGUKrzKtTurAGN0ICoDg\&usg=AFQjCNG5LC3ExDucQTEPTJpEZmN5PZoj0Q }}$

HARMAN, Graham., The Prince of Networks. Bruno Latour and Metaphysics. Re.Press, Melbourne, 2009.

HARMAN, Graham., The Quadruple Object. Winchester (UK), Zero Books., 2011

HEIDEGGER, Martin. Essais et conférences. Paris, Gallimard, 1958.

LATOUR, Bruno. Science In Action: How to Follow Scientists and Engineers through Society. Cambridge, Mass.: Harvard University Press. 1987.

LATOUR, Bruno. Reassembling the Social. An introduction to Actor-Network Theory. Oxford University Press, NY. 2005.

LATOUR, Bruno. La mondialisation fait-elle un monde habitable? in Revue Territoires 2040., n. 2, disponível em http://territoires2040.datar.gouv.fr/spip.php?article60\&revue=1, 2011.

LEMOS, André. Você está aqui! Mídia Locativa e teorias "Materialidades da Comunicação" e "Ator-Rede". in Revista Comunicação e Sociedade, São Bernardo do Campo, SP, Metodista, Ano 32, Número 54, jul./dez. 2010. pp. 5-29.

MEILLASSOUX, Quentin. After Finitude. An Essay on the Necessity of Contingency. Continuum, London, NY., 2008. Kindle Version. 